\title{
Cost-effectiveness Analysis of the Integrated Control Strategy for Schistosomiasis Japonica in Lake Region of China: a Jiangling Case Study
}

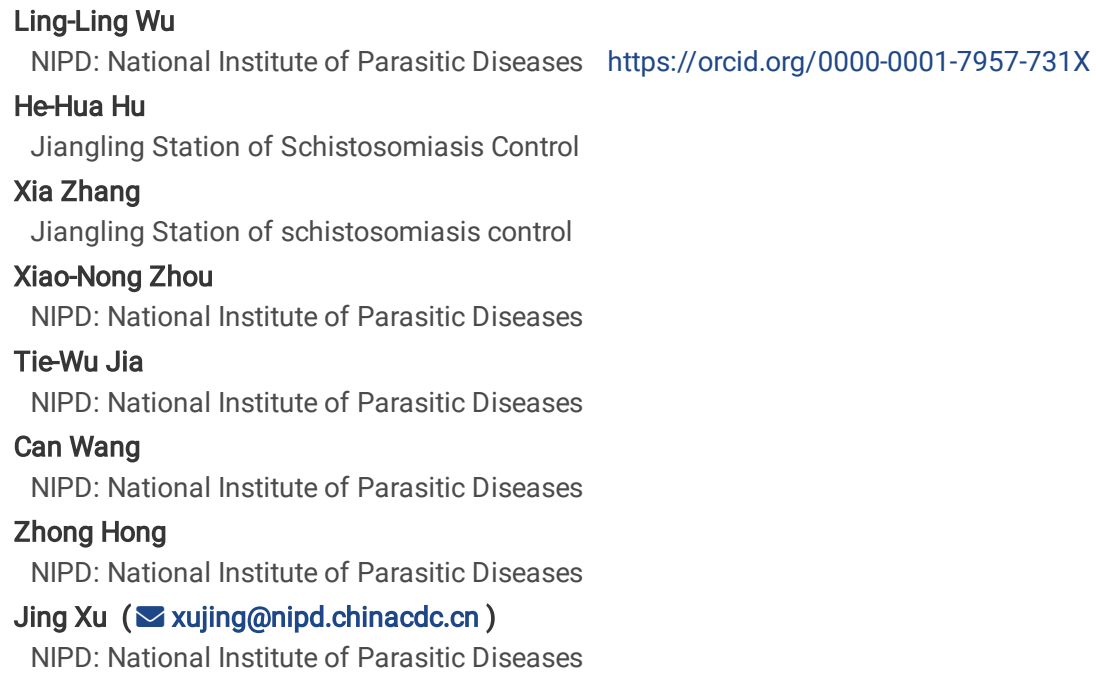




\section{Abstract}

Background: Under the condition of low epidemic level and limited funding, it is urgent to carry out health economic evaluation on the integrated schistosomiasis control strategy currently implemented in lake region in order to rationally allocate and utilize health resources and maximize benefits. The objective of this study is to provide reference for understanding the effectiveness of the integrated control strategy and adjusting prevention and control strategies or measures.

Methods: The investment in schistosomiasis control and disability adjusted life years $\triangle \mathrm{DALYs} \llbracket$ caused by schistosomiasis were calculated. Incremental costeffectiveness ratio (ICER) was conducted through calculating the incremental cost of every additional case averted, the incremental cost of every additional DALY averted through implementation of the integrated schistosomiasis control at different control stages in Jiangling County.

Results: The total expenditure for schistosomiasis control in Jiangling County from 2009 to 2019 was 607 million Chinese yuan (CNY). The average annual costs for schistosomiasis prevention and control in stages of morbidity control (2009-2012), transmission control (2013-2016), and transmission interruption (2017-2019) were 41.98 million CNY $\$ 90.19$ million CNY and 26.06 million CNY respectively. The overall disease burden caused by schistosomiasis presented a downward trend. Meanwhile, the disease burden of advanced cases showed an upward trend with the DALY increased from 943.72 to1031.59 person-years. Most disease burden occurred in the age group over 45 years old (especially the elderly over 60 years old). Taking the morbidity control stage as an analysis control, incremental cost-effectiveness analysis (ICEA) showed that the cost increased by 8505.5 CNY and decreased by 2217.6 CNY respectively to avert one additional case in transmission control stage and transmission interruption stage respectively in Jiangling County. Correspondingly, to avert one additional DALY, the cost increased by 73937.6 CNY and decreased by 21508.6 CNY respectively.

Conclusions: As the epidemic declines, the integrated prevention and control strategy is more cost-effective. Surveillance and management on elder population should be strengthened to avert higher diseases burden.

\section{Background}

The implementation of integrated prevention and control strategy focusing on the source of infection to interrupt the transmission of schistosomiasis had strongly accelerated the process of schistosomiasis control in People's Republic of China (P.R. China) [1]. Morbidity control (the infection rate of humans and livestock in epidemic villages $<5 \%$ ) and transmission control (the infection rate of humans and livestock in epidemic villages $<1 \%$ ) were reached nationwide in 2008 and 2015 respectively [2, 3]. By the end of 2019, 95.3\% of the epidemic counties in P.R. China had reached the threshold of transmission interruption or elimination according to the national standards [4]. The endemicity of schistosomiasis had dropped to the lowest level in history. At present, the key areas for schistosomiasis prevention and control in P.R. China are distributed along the middle and lower reaches of the Yangtze River, as well as the areas of Dongting Lake and Poyang Lake.

Under the condition of low epidemic level and limited funding, it is urgent to carry out health economic evaluation on the integrated schistosomiasis control strategy currently implemented in lake region in order to rationally allocate and utilize health resources and maximize benefits.[5] The health economics evaluation refers to the evaluation and selection of alternatives by analyzing the economic effects (cost, effect or input, output) of health planning.[6] The methods used to evaluate the economic value of disease interventions mainly include cost-effectiveness analysis (CEA), cost-utility analysis (CUA), costbenefit analysis (CBA) and cost-minimization analysis (CMA). CBA of schistosomiasis is relatively difficult because of the complexity of identifying and quantifying the health benefits of schistosomiasis prevention and control [7, 8]. In P.R. China, there have been several studies on the effectiveness of integrated prevention and control strategies for schistosomiasis, but there are few related to cost-effectiveness analyses [9].

As periodic assessment and analysis of resource utilization are conducive to the optimization of diseases prevention and control [10, 11]. We evaluated the cost-effectiveness of the integrated control strategy for schistosomiasis taking Jiangling County as an example due to its heavy endemicity of schistosomiasis in history and well archived data and documents, thus to provide reference for understanding the effectiveness of the integrated control strategy and adjusting diseases prevention and control strategies or measures.

\section{Materials And Methods}

\section{Setting}

Jiangling county of Hubei Province, a typical marshland and lake region used to be a heavily endemic area of schistosomiasis, locates in the middle reaches of the Yangtze River and near the north bank of the Jingjiang River. It belongs to the hinterland of the four lakes (Long Lake, Three Lakes, Egret Lake, Hong Lake), having rich water system and complex natural environments suitable for snails breeding. Through the implementation of the integrated control strategy for schistosomiasis control, the county has reached the criteria of morbidity control, transmission control and transmission interruption in 2008,2013 and 2017, respectively [12-14], keeping a low level of schistosomiasis endemicity until now.

\section{Data collection}

Data reflecting the epidemic status of schistosomiasis and costs for schistosomiasis control in Jiangling County from 2009 to 2019 were collected from the perspective of health investors.

Data including the number of schistosomiasis cases (acute cases, chronic cases and advanced cases), the snails' infested area, the infected snails infested areas etc. were collected during 2009-2019. The general demographic information especially the age of each schistosomiasis cases were collected. For schistosomiasis control investment, data reflecting the costs of case detection and treatment, snail control, health education, risk monitoring, livestock 
elimination and control, toilets modification and integrated management in Jiangling County from 2009 to 2019 were collected [15-18]. The costs of case detection and treatment were composed of the annual costs of questionnaire survey, blood examination, stool examination, treatment against schistosomiasis, involving the costs of subsidies, diagnostic reagents and materials, drug, medical assistance for advanced cases of schistosomiasis and so on. The costs of snail control included the costs for conducting snails' survey and mollusciciding, involving the costs of subsidies, materials, drug and so on. Health education expenses included the costs for conducting training courses for school students, village cadres and doctors, the costs for preparing and distributing the leaflets, setting the warning signs etc. As for integrated interventions, data reflecting the investment related to schistosomiasis control activities were collected from the departments of agriculture, forestry, water conservancy, transportation and land resources.

\section{Data management and statistical analyses}

Data collected was entered and descriptive analysis was conducted by Microsoft Excel 2016 software.

The Disability Adjusted Life Years (DALY) was used to quantify the burden of disease, which was calculated with the life quality method based on disability weight (DW) got from cases' life quality assessment.[19] The formula was listed as follows [20]:

\section{DALYA $=Y L D+Y L L, Y L D p r e v x=\Sigma P X^{\star} D W x, Y L L=N^{*} L$}

Where YLD is the years lived with disability, YLL is the years of life lost, YLDprev $x$ is the years lived with disability based on prevalence (prev is the abbreviation of prevalence, $x$ is the grouping variable), $P x$ is the number of cases in the reference population at a specific time. DWx is the disability weight of health outcomes. The DW of different age groups of advanced schistosomiasis cases was calculated as the following criteria: $30-44$ years old (0.378), $45-59$ years old (0.399), over 60 years old (0.510) [21]. The DW of different age groups of chronic cases of schistosomiasis was standardized as the follows: $5-14$ years old (0.095), 15-44 years old (0.159), 45-59 years old (0.207), over 60 years old (0.246) [22]. $N$ is the number of deaths in different age groups and genders; $L$ is the life loss value of each age group, that is, the life expectancy value corresponding to the death age point in the standard life table.

For incremental cost-effectiveness analysis (ICEA), the discount formula of the current year was calculated according to formula : $\mathrm{Cn}=\mathrm{Cn} /(1+\mathrm{r}) \mathrm{n}[23]$, where $\mathrm{Cn}^{\prime}$ is the discounted cost; $\mathrm{Cn}$ is the actual cost of each year; $r$ is the discount rate, often using the current bank's regular interest rate; $\mathrm{n}$ is the year. Incremental cost-effectiveness ratio (ICER) was used as the effect indicator [24-26], that was, the incremental cost for each additional case averted and the incremental cost for each additional DALY averted.

\section{Results}

\section{General information of schistosomiasis epidemic situation in Jiangling County}

From 2009 to 2019, the endemicity of schistosomiasis in Jiangling County presented a downward trend. The number of positives with antibodies against schistosome dropped from 13, 086 in 2009 to 2, 310 in 2019, while the number of stool positives finding Schistosoma japonicum eggs decreased from 2, 158 in 2009 to 0 in 2019. In addition, the number of advanced schistosomiasis cases dropped from 1, 248 in 2009 to 1, 073 in 2019 , while no acute schistosomiasis case was reported since 2008 in the county. The snail infested area had declined from $3030.73 \mathrm{hm} 2$ in 2009 to $2718.04 \mathrm{hm} 2$ in 2019 , and no infected snail was detected since 2012.

Table 1

Changes of schistosomiasis cases and snails' status in Jiangling County during 2009 to 2019

\begin{tabular}{|c|c|c|c|c|}
\hline \multirow[t]{2}{*}{ Year } & \multicolumn{2}{|l|}{ Disease situation } & \multicolumn{2}{|l|}{ Snail situation } \\
\hline & No. positives of stool exams & No. advanced cases of schistosomiasis & Snail area $\left(\mathrm{hm}^{2}\right)$ & $\begin{array}{l}\text { Area with infected } \\
\text { snails }\left(\mathrm{hm}^{2}\right)\end{array}$ \\
\hline 2009 & 2158 & 1118 & 3030.73 & 136.68 \\
\hline 2010 & 1602 & 1140 & 3030.23 & 133.06 \\
\hline 2011 & 1199 & 1169 & 3029.53 & 51.51 \\
\hline 2012 & 573 & 1180 & 2875.86 & 0.00 \\
\hline 2013 & 395 & 1187 & 2875.86 & 0.00 \\
\hline 2014 & 229 & 1222 & 2875.86 & 0.00 \\
\hline 2015 & 74 & 1233 & 2728.65 & 0.00 \\
\hline 2016 & 0 & 1205 & 2728.65 & 0.00 \\
\hline 2017 & 0 & 1111 & 2718.10 & 0.00 \\
\hline 2018 & 0 & 1098 & 2718.04 & 0.00 \\
\hline 2019 & 0 & 1073 & 2718.04 & 0.00 \\
\hline Total & 6230 & 12736 & 31329.55 & 321.25 \\
\hline
\end{tabular}


The overall expenditure for schistosomiasis control in Jiangling County from 2009 to 2019 was 607 million CNY, of which the costs from the land resources department for schistosomiasis control was the largest (336 million), followed by costs for health activities for schistosomiasis control (109 million). Among the investment from health department for schistosomiasis control, costs of snail control, case treatment, cattle disposal and control accounted for $35.3 \%$ (3826.15/10855.32), 22.7\% (2466.15/10855.32), and 22.6\% (2447.60/10855.32) respectively. For investments from other departments, the costs related to land modification, transportation and water conservancy projects accounted for $67.6 \%$ (33648.82/60688.43), $13.9 \%$ (6911.38 /60688.43) and 10.1\% $(5050.17 / 60688.43)$.

From 2009 to 2019, the average annual costs of schistosomiasis prevention and control were 55.17 million CNY. Calculating the costs by the disease control stage, the costs in the stage of morbidity control (2009-2012), transmission control (2013-2016), and transmission interruption (2017-2019) were 41.98 million CNY, 90.19 million CNY and 26.06 million CNY respectively, showing the annual costs of schistosomiasis prevention and control were the lowest after Jiangling County reached the criteria of transmission interruption. (Table 2)

Table 2

Schistosomiasis control investment in Jiangling Country from 2009 to 2019(CNY 10000 )

\begin{tabular}{|c|c|c|c|c|c|c|c|c|c|c|c|c|}
\hline Expense item & & 2009 & 2010 & 2011 & 2012 & 2013 & 2014 & 2015 & 2016 & 2017 & 2018 & \& \\
\hline \multirow{10}{*}{$\begin{array}{l}\text { Special funds } \\
\text { for health } \\
\text { schistosomiasis } \\
\text { control }\end{array}$} & $\begin{array}{l}\text { Costs of case } \\
\text { searching }\end{array}$ & 33.57 & 39.33 & 40.67 & 79.13 & 70.59 & 77.81 & 87.96 & 39.99 & 47.23 & 46.38 & $\varepsilon$ \\
\hline & $\begin{array}{l}\text { Costs of case } \\
\text { treatment }\end{array}$ & 255.47 & 244.07 & 229.69 & 217.77 & 217.14 & 226.21 & 230.58 & 236.73 & 213.54 & 199.90 & 1 \\
\hline & $\begin{array}{l}\text { Costs of } \\
\text { snails' survey }\end{array}$ & 37.64 & 39.18 & 43.42 & 33.44 & 38.90 & 33.31 & 79.46 & 80.35 & 67.59 & 54.03 & ร \\
\hline & $\begin{array}{l}\text { Costs of } \\
\text { mollusciciding }\end{array}$ & 134.00 & 236.67 & 710.96 & 355.30 & 434.35 & 319.81 & 322.98 & 279.00 & 397.85 & 313.36 & $\Xi$ \\
\hline & $\begin{array}{l}\text { Costs of } \\
\text { health } \\
\text { education }\end{array}$ & 11.25 & 12.76 & 9.76 & 10.72 & 11.08 & 7.33 & 5.65 & 9.81 & 7.87 & 9.27 & ; \\
\hline & $\begin{array}{l}\text { Costs of } \\
\text { livestock } \\
\text { disposal and } \\
\text { management }\end{array}$ & 132.00 & 1376.86 & 344.56 & 59.75 & 101.66 & 172.99 & 141.06 & 18.07 & 17.68 & 74.32 & $\varepsilon$ \\
\hline & $\begin{array}{l}\text { Costs of } \\
\text { toilets } \\
\text { modification }\end{array}$ & 200.01 & 283.66 & 0.00 & 0.00 & 0.00 & 0.00 & 0.00 & 0.00 & 0.00 & 0.00 & c \\
\hline & $\begin{array}{l}\text { Costs of risk } \\
\text { monitoring }\end{array}$ & 0.00 & 0.00 & 0.00 & 0.00 & 0.00 & 35.55 & 34.59 & 46.43 & 40.17 & 34.38 & $\varepsilon$ \\
\hline & Others & 12.25 & 21.03 & 12.96 & 12.64 & 17.18 & 11.52 & 10.81 & 11.40 & 13.85 & 9.82 & $\underline{c}$ \\
\hline & Subtotal & 816.18 & 2253.56 & 1392.02 & 768.75 & 890.90 & 884.53 & 913.08 & 721.78 & 805.78 & 741.46 & $\epsilon$ \\
\hline \multirow[t]{6}{*}{$\begin{array}{l}\text { Costs for } \\
\text { integrated } \\
\text { control }\end{array}$} & $\begin{array}{l}\text { Costs of } \\
\text { agricultural } \\
\text { projects }\end{array}$ & 60.00 & 1334.28 & 478.24 & 187.09 & 0.00 & 304.19 & 321.58 & 175.76 & 217.14 & 128.64 & 1 \\
\hline & $\begin{array}{l}\text { Costs of } \\
\text { forestry } \\
\text { projects }\end{array}$ & 0.00 & 0.00 & 0.00 & 328.65 & 127.58 & 71.58 & 131.25 & 102.69 & 54.40 & 49.11 & $\angle$ \\
\hline & $\begin{array}{l}\text { Costs of water } \\
\text { conservancy } \\
\text { projects }\end{array}$ & 72.80 & 811.44 & 2104.34 & 0.00 & 0.00 & 501.04 & 420.01 & 299.52 & 242.71 & 342.14 & 2 \\
\hline & $\begin{array}{l}\text { Costs of } \\
\text { transporation } \\
\text { projects }\end{array}$ & 216.00 & 49.88 & 3098.98 & 763.31 & 768.47 & 232.63 & 455.01 & 616.15 & 150.65 & 70.39 & $L$ \\
\hline & $\begin{array}{l}\text { Costs of land } \\
\text { modification } \\
\text { projects }\end{array}$ & 0.00 & 0.00 & 0.00 & 2057.94 & 4116.80 & 7985.31 & 10195.78 & 5840.63 & 3452.37 & 0.00 & c \\
\hline & Subtotal & 348.80 & 2195.60 & 5681.55 & 3336.98 & 5012.85 & 9094.74 & 11523.64 & 7034.75 & 4117.28 & 590.28 & $\varepsilon$ \\
\hline \multicolumn{2}{|l|}{ Total } & 1164.98 & 4449.16 & 7073.58 & 4105.74 & 5903.75 & 9979.27 & 12436.72 & 7756.54 & 4923.05 & 1331.74 & 1 \\
\hline
\end{tabular}


The overall disease burden caused by schistosomiasis presented a downward trend with DALYs decreased from 3178.38 person-years in 2009 to 1497.42 person-years in 2019. Calculating the disease burden by the types of schistosomiasis cases, the DALYs of chronic cases of schistosomiasis presented a downward trend (2234.66 465.83 person-years), while that of advanced cases showed an upward trend (943.72 1031.59 person-years) with a small peak in 2017. In addition, the variation trend in total DALYs of schistosomiasis was consistent with that of chronic cases before 2013 , but shifted to be consistent with that of advanced cases after 2013. (Fig. 1)

According to DW, the schistosomiasis cases in Jiangling County from 2009 to 2019 were divided into 4 age groups: 6-14 years old, 15-44 years old, $45-59$ years old and $\geq 60$ years old. The YLD in the 15-44 and 45-59 age groups presented an obvious downward trend (722.03 34.28, $1285.41 \sim 295.60$ personyears), while fluctuated a little bit in the age group of 60 years old and above, in the range of 460 and 800 person-years. Since 2015 , the YLD was mainly concentrated in the age group of 60 years old and above, accounted for $45.8 \%$ [43.9\% (541.75/1233.77), 45.4\% (625.43/1377.00), 47.2\% (521.53/1103.92), $43.5 \%$ (461.47/1060.85), 49.0\% (471.23/962.36)] on average, while the YLD in the age groups of 15-44 years old, under 15 years old accounted for $7.2 \%$ [9.3\% (114.50/1233.77), 9.2\% (126.16/1377.00), 7.0\%(77.16/1103.92), 6.8\%(71.85/1060.85), 3.6\%(34.28/962.36] and 0.0\% [0.0\% (0.48/1233.77), 0.1\% (0.76/1377.00), 0.0\%(0.19/1103.92), 0.0\%(0.29/1060.85), 0.0\%] on average (Fig. 2).

\section{ICEA of integrated schistosomiasis control}

Taking the morbidity control stage as an analysis control, ICEA based on the number of schistosomiasis cases showed that the costs increased by 8505.5 CNY and decreased by 2217.6 CNY respectively to avert one additional case in transmission control stage and transmission interruption stage respectively in Jiangling County (Table 3). The integrated control strategy was more cost-effective in transmission interruption stage.

Table 3

Incremental cost-effectiveness analysis of integrated control strategies in different stages of schistosomiasis-number of cases

\begin{tabular}{|c|c|c|c|c|c|}
\hline $\begin{array}{l}\text { Stage of } \\
\text { schistosomiasis } \\
\text { control }\end{array}$ & $\begin{array}{l}\text { Annual number of } \\
\text { cases per year }\end{array}$ & $\begin{array}{l}\text { Average number of cases } \\
\text { averted per year }\end{array}$ & $\begin{array}{l}\text { Average } \\
\text { annual cost } \\
\text { (CNY } 10 \\
\text { OOO) }\end{array}$ & $\begin{array}{l}\text { Incremental } \\
\text { cost } \\
\text { (CNY } 10 \\
\text { O00) }\end{array}$ & $\begin{array}{l}\text { ICER(CNY)(incremental cost/average } \\
\text { number of cases averted per year }\end{array}$ \\
\hline $\begin{array}{l}\text { Morbidity control } \\
\text { stage } \\
(2009-2012)\end{array}$ & 10897.0 & - & 4198.4 & - & - \\
\hline $\begin{array}{l}\text { Transmission } \\
\text { control stage } \\
(2013-2016)\end{array}$ & 5229.3 & 5667.8 & 9019.1 & 4820.7 & 8505.5 \\
\hline $\begin{array}{l}\text { Transmission } \\
\text { interruption stage } \\
(2017-2019)\end{array}$ & 3717.3 & 7179.7 & 2606.2 & -1592.1 & -2217.6 \\
\hline
\end{tabular}

Taking the morbidity control stage as an analysis control, ICEA based on the DALY showed that the cost increased by 73937.6 CNY and decreased by 21508.6 CNY respectively to avert one additional DALY in transmission control stage and transmission interruption stage respectively in Jiangling County (Table 4). The integrated control strategy was more cost-effective in transmission interruption stage.

Table 4

Incremental cost-effectiveness analysis of integrated control strategies in different stages of schistosomiasis- disability adjusted life years

\begin{tabular}{|c|c|c|c|c|c|}
\hline Stage of schistosomiasis control & $\begin{array}{l}\text { Cost (CNY } 10 \\
000)\end{array}$ & $\begin{array}{l}\text { Incremental cost (CNY } \\
10000)\end{array}$ & $\begin{array}{l}\text { DALYs } \\
\text { (person- } \\
\text { year) }\end{array}$ & $\begin{array}{l}\text { DALYs averted } \\
\text { (person-year) }\end{array}$ & $\begin{array}{l}\text { ICER(CNY) } \\
\text { (incremental cost / DALYs } \\
\text { averted) }\end{array}$ \\
\hline $\begin{array}{l}\text { Morbidity control stage } \\
(2009-2012)\end{array}$ & 16793.5 & - & 10257.2 & - & - \\
\hline $\begin{array}{l}\text { Transmission control stage } \\
(2013-2016)\end{array}$ & 36076.3 & 19282.8 & 7649.2 & 2608.0 & 73937.6 \\
\hline $\begin{array}{l}\text { Transmission interruption } \\
\text { stage(2017-2019) }\end{array}$ & 7818.7 & -8974.8 & 6084.6 & 4172.6 & -21508.6 \\
\hline
\end{tabular}

\section{Discussion}

The transmission of schistosomiasis is affected by biological, natural and social factors, thus determining that the control of schistosomiasis is a systematic social project, involving many departments, such as agriculture, forestry, water conservancy, land resources etc. Although the integrated control strategy 
focusing on the source of infection to block the transmission of schistosomiasis has been implemented in P. R. China more than ten years, it's relatively difficult to carry out a systematic health economic evaluation on the integrated control strategy. The economic evaluation indices of schistosomiasis control measures reported in previous studies were mainly the costs for reducing the infection rate of $S$. japonicum in residents, livestock, snails, or the costs for reducing the integrated impact index of schistosomiasis. [27-29] However, in current situation, the majority of schistosomiasis cases are advanced cases in P.R. China, featured with a long process of pathological changes and neglected impacts on residents' health. Thus previous evaluation indices were no longer applicable. In our study, the CEA of the integrated control strategy for schistosomiasis was conducted through calculating the indices of DALY and ICER, taking Jiangling County as an example, to explore the burden of schistosomiasis on population more scientifically and comprehensively.

The analysis of schistosomiasis investment in different periods in Jiangling County found that the average annual costs of schistosomiasis prevention and control in stages of morbidity control, transmission control and transmission interruption were 41.98 million CNY, 90.19 million CNY and $26.06 \mathrm{CNY}$ respectively, equivalent to the annual per capita investment in schistosomiasis control of $123.08 \mathrm{CNY}, 270.27 \mathrm{CNY}$ and $77.29 \mathrm{CNY}$ respectively, if considering the number of average annual resident population(341 100, 333 700, and 337200 in corresponding periods). Due to the large one-time investment in environmental improvement projects, the overall investment in schistosomiasis control was relatively high [30], but still reasonable from the perspective of population-based protection through prevention and control activities. The study showed that the investment in schistosomiasis control decreased significantly after Jiangling reached the threshold of transmission interruption. The rising prices of materials and labors may further deepen the gap between investment and actual demand of schistosomiasis control.

Because there has been no acute schistosomiasis cases in Jiangling County since 2009, the disease burden only included the DALYs of chronic and advanced schistosomiasis in this study. The DALYs of chronic schistosomiasis was mainly based on YLD caused by schistosomiasis rather than YLL [31]. In addition, we took the mean value (0.177) as the DW of a few cases as their age information missed in this study. Our study found that the overall disease burden caused by schistosomiasis presented a downward trend. To the opposite, the disease burden of advanced cases showed an upward trend, which can be explained by that YLL of advanced cases increased from 377.40 person-years in 2009 to 535.06 person-years in 2019 . Also a small peak was presented in 2017 because 137 advanced cases were dead in that year (137 died cases), resulting in a larger YLL. In addition, the current YLD of schistosomiasis in Jiangling County mainly distributed in the age group of 60 years and over, followed by the age group of $45-59$ years. The aging trend of cases was obvious, which was consistent with existing researches [32,33]. With the improvement of treatment quality and strengthening of medical assistance for advanced cases in P.R. China, the life expectancy of advanced cases will extend. As aging is an important factor affecting life quality and disease burden, it is necessary to strengthen dynamic monitoring and management of the elder age group through regular follow-up and healthy education. Early detection of advanced cases and timely interventions when the disease progression was found, are required to avert further deterioration leading to more disease burden.

Taking the morbidity control stage as an analysis control, the ICEA of the integrated prevention and control strategy for schistosomiasis in Jiangling County showed that the costs increased by $8505.5 \mathrm{CNY}$ and decreased by $2217.6 \mathrm{CNY}$ respectively to avert one additional case in transmission control stage and transmission interruption stage respectively. Correspondingly, to avert one additional DALY, the costs increased by $73937.6 \mathrm{CNY}$ and decreased by 21508.6 CNY respectively. These results all indicated that the strategy in the transmission interruption stage was the most cost-effective. Although the investment was relatively high in early stage, the disease burden decreased significantly due to the implementation of this strategy. As the endemicity of schistosomiasis declines, this strategy is more cost-effective. Therefore, multiple section collaboration and resource integration should be strengthened further and investments in the schistosomiasis integrated prevention and control should be continued to facilitate the elimination of schistosomiasis.

There are some limitations of our study. First, being a retrospective research, a few data are missing because of the large time span. In this paper, the mean substitution was used to deal with the missing value, which may lead to a possible error with the real value, but it's unavoidable. Second, the investment in human resources and fixed equipment, are not included in the cost calculation due to its complicity of definition, which may impact on the findings. It is suggested to strengthen the recording and archiving of relevant data in the future in order to improve the quality of similar research thus to better guide on-site prevention and control.

\section{Conclusions}

Although the investment was relatively high in early stage of schistosomiasis control, the disease burden decreased significantly due to the implementation of the integrated prevention and control strategy. As the epidemic declines, this strategy is more cost-effective. Thus, multiple section collaboration and resource integration should be strengthened further and investments in the schistosomiasis integrated prevention and control should be continued to facilitate the elimination of schistosomiasis. In addition, the current disease burden of schistosomiasis mainly distributed in the elder age group. Early detection of advanced cases and timely interventions when the disease progression was found, are required to avert further deterioration leading to more disease burden.

\section{Abbreviations}

CEA: Cost-effectiveness analysis; CUA: Cost-utility analysis; CBA: Cost-benefit analysis; CMA: Cost-minimization analysis; DALY: Disability adjusted life years; DW: Disability weight; YLD: Years lived with disability; YLL: Years of life lost; ICEA: Incremental cost-effectiveness analysis; ICER: Incremental costeffectiveness ratio; S. japonicum: Schistosoma japonicum; P.R. China: People's Republic of China; CNY: Chinese yuan.

\section{Declarations}

\section{Acknowledgements}

We thank the staffs for their efforts and assistances in data collection in the Jiangling Station of Schistosomiasis Control. 


\section{Ethics approval and consent to participate}

Not applicable.

\section{Consent for publication}

Not applicable.

\section{Availability of data and materials}

All the relevant data generated during this study are included in the manuscript.

\section{Competing interests}

Xiao-Nong Zhou is the Editor-in-Chief of Infectious Diseases of Poverty. He was not involved in the peer-review or handling of the manuscript. The authors have no other competing interests to disclose.

\section{Funding}

This study was supported by the National Science and Technology Major Project of China ((No. 2018ZX10101002-002) and the National Natural Science Foundation of China (No. 82073619). The funding sources have no role in any aspect of this study.

\section{Authors' contributions}

WLL, ZXN, JTW and XJ conceived and designed the study. WLL, HHH and ZX participated in data collection. WLL WC and HZ carried out the data analyses and wrote the first draft manuscript. WLL and XJ revised the paper. WLL, WC and HZ translated the manuscript. All authors read and approved the final manuscript.

\section{References}

1. Wang LD. Promotion of strategy transition for national schistosomiasis control programme by implementation of the regulation of schistosomiasis control in China. Chinese Journal of Preventive Medicine. 2006;40(4): 219-220.

2. Hao Y, Zheng H, Zhu R, Guo JG, Wu XH, Wang LY, et al. Schistosomiasis status in People's Republic of China in 2008. Chinese Journal of Schistosomiasis Control. 2009;21(6): 451-456.

3. Zhang LJ, Xu ZM, Qian YJ, Dang H, Lü S, Xu J, Li SZ, et al. Endemic status of schistosomiasis in People's Republic of China in 2015. Chinese Journal of Schistosomiasis Control. 2016;28(6): 611-617.

4. Zhang LJ, Xu ZM, Dang H, Li YL, Lü S, Xu J, et al. Endemic status of schistosomiasis in People's Republic of China in 2019. Chinese Journal of Schistosomiasis Control. 2020; 32(6)

5. Secor WE, Colley DG. When Should the Emphasis on Schistosomiasis Control Move to Elimination? Trop Med Infect Dis. 2018;3(3):85.

6. Chen W. Health Economics, 4rd ed.; People's Medical Publishing House, Beijing, 2017.p.383.

7. Zhou XN, Wang LY, Chen MG, Wang TP, Guo JG, Wu XH, et al. An economic evaluation of the national schistosomiasis control programme in China from 1992 to 2000. Acta Trop. 2005;96: 255-265.

8. Turner HC, French MD, Montresor A, King CH, Rollinson D, Toor J. Economic evaluations of human schistosomiasis interventions: a systematic review and identification of associated research needs. Wellcome Open Res. 2020;5:45.

9. Conteh L, Engels T, Molyneux DH. Socioeconomic aspects of neglected tropical diseases. Lancet. 2010;375: $239-247$.

10. Yu Q, Guo JG. Development of healthy economics and its application in the control of schistosomiasis in China. Chinese Journal of Parasitic Disease Control. 2004;17(4): 254-255.

11. Huang YX, Manderson L. The social and economic context and determinants of schistosomiasis japonica. Acta Trop. 2005;96: 223-231.

12. Tu ZW, Dai YH, Huang XB, Liu JB, Liu HC, Zhu HG, et al. Evaluation for Epidemic Situation of Schistosomiasis Control in Hubei Province in 2008. Journal of Tropical Medicine. 2009; (03): 96-99.

13. Xiao Y, Zhang J, Chen YY, Zhou XR, Tang L, He H, et al. Evaluation of transmission control of schistosomiasis in 19 counties $₫$ cities, districts $₫$ of Hubei Province in 2013. Chinese Journal of Schistosomiasis Control. 2016;28(05): 513-518.

14. Zhang LJ, Xu ZM, Dai SM, Dang H, Lü S, Xu J, et al. Endemic status of schistosomiasis in People's Republic of China in 2017. Chinese Journal of Schistosomiasis Control. 2018;30(5): 481-488.

15. Zhu JY, Wang CX, Wang CF, Wang SZ, Lu K, Hu JX, et al. Cost $囚$ effectiveness of schistosomiasis comprehensive control in Lushan County from2007 to 2012. Chinese Journal of Schistosomiasis Control. 2013;25(5): 513.

16. Zhang HM, Yu Q, Zhang X, Cao CL, Li SZ, Zhu H. Cost-effectiveness evaluation on comprehensive control measures carrying out in schistosomiasis endemic areas with regard to different layers of administrative villages stratified by infection situation of human and domestic animals $₫$ Costeffectiveness study in inner embankment of marshland and lake regions from 2006 to 2010. Chinese Journal of Schistosomiasis Control. 2014;26(3): 254-259. 
17. Yu Q, Zhao GM, Hong XL, Lutz EA, Guo JG. Impact and cost-effectiveness of a comprehensive Schistosomiasis japonica control program in the Poyang Lake region of China. Int J Environ Res Public Health. 2013;10(12):6409-21.

18. Salari P, Fürst T, Knopp S, Utzinger J, Tediosi F. Cost of interventions to control schistosomiasis: A systematic review of the literature. PLoS Negl Trop Dis. 2020;14(3):e0008098.

19. Li YT, Cai XT, Zhu JH, Sun LP, Hua HY, Tian LG, et.al. Approaches used for assessment of the burden of advanced schistosomiasis japonica:a comparative study. 2019;31(3):280-284, 290.

20. King CH., Galvani AP. Underestimation of the global burden of schistosomiasis. Lancet. 2018;391: 307-308.

21. Jia TW, Utzinger J, Deng Y, Yang K, Li YY, Zhu JH, et al. Quantifying quality of life and disability of patients with advanced schistosomiasis japonica. PLoS Negl Trop Dis. 2011;5: e966.

22. Jia TW, Zhou XN, Wang XH, Utzinger J, Steinmann P, Wu XH. Assessment of the age-specific disability weight of chronic schistosomiasis japonica. Bull World Health Organ. 2007;85: 458-465.

23. Department of Disease Control. Schistosomiasis Control Manual, 3rd ed.; Shanghai Science and Technology Press, Shanghai, 2000. p. $263-264$.

24. Lo NC, Gurarie D, Yoon N, Coulibaly JT., Bendavid E, Andrews JR., et al. Impact and cost-effectiveness of snail control to achieve disease control targets for schistosomiasis. Proc Natl Acad Sci U S A. 2018;115: E584-E591.

25. Lo NC, Bogoch II, Blackburn BG, Raso G, N'Goran EK, Coulibaly JT. Comparison of community-wide, integrated mass drug administration strategies for schistosomiasis and soil-transmitted helminthiasis: a cost-effectiveness modelling study. The Lancet Global Health. 2015;3: e629-e638.

26. De Neve JW, Andriantavison RL, Croke K, Krisam J, Rajoela VH, Rakotoarivony RA, Rambeloson V, et.al. Health, financial, and education gains of investing in preventive chemotherapy for schistosomiasis, soil-transmitted helminthiases, and lymphatic filariasis in Madagascar: A modeling study. PLoS Negl Trop Dis. 2018;12(12):e0007002.

27. Luo TP, Zhou XN, Qiu ZL. Cost-effectiveness and cost-benefit of integrated schistosomiasis control strategy with emphasis on infectious source control in mountainous areas of Yunnan Province. Chinese Journal of Schistosomiasis Control. 2009;21(2): 93-97.

28. Yang Ya, Li JB, Liu H, Li SD, He Z, Cai B, et al. Cost-effectiveness of comprehensive schistosomiasis control strategy with focus on cattle and sheep removal in Junshan District, Yueyang City. Chinese Journal of Schistosomiasis Control. 2018;30(1): 14-17.

29. Yu Q, Wan XX, Liu Q, Wang ZX, Huang YQ, Guo JG. Cost-effectiveness evaluation and investigation on control measures improvement in areas of schistosomiasis transmission control in hilly regions of mountains $₫$. Chinese Journal of Disease Control \& Prevention. 2013;17(8): 706-710.

30. Zhang SQ, He JC, Wang TP, Chen GG, Pan XP, Bao JG, et al. Effect of comprehensive schistosomiasis control measures with emphasis on infectious source control carried out in different scale regions. Journal of Tropical Disease and Parasitology.2011;9(3): 63-68.

31. Murray CJL., Salomon J, Lopez A. (2002). Summary measures of population health: concepts, ethics, measurement and applications.

32. Li FY, Tan HZ, Zhou J, Zhou RH, Zhu JH, Cai XT, Ren GH, et al. Analysis of characteristics of medical assistance to advanced schistosomiasis patients in Hunan Province, 2015. Chinese Journal of Schistosomiasis Control. 2017 ;29(3):281-285.

33. Yuan Y, Zhou T. Survey on 202 patients with advanced schistosomiasis in Anqing area in 2017. Journal of Tropical Disease and Parasitology .2018;16(4): 204-206.

\section{Figures}

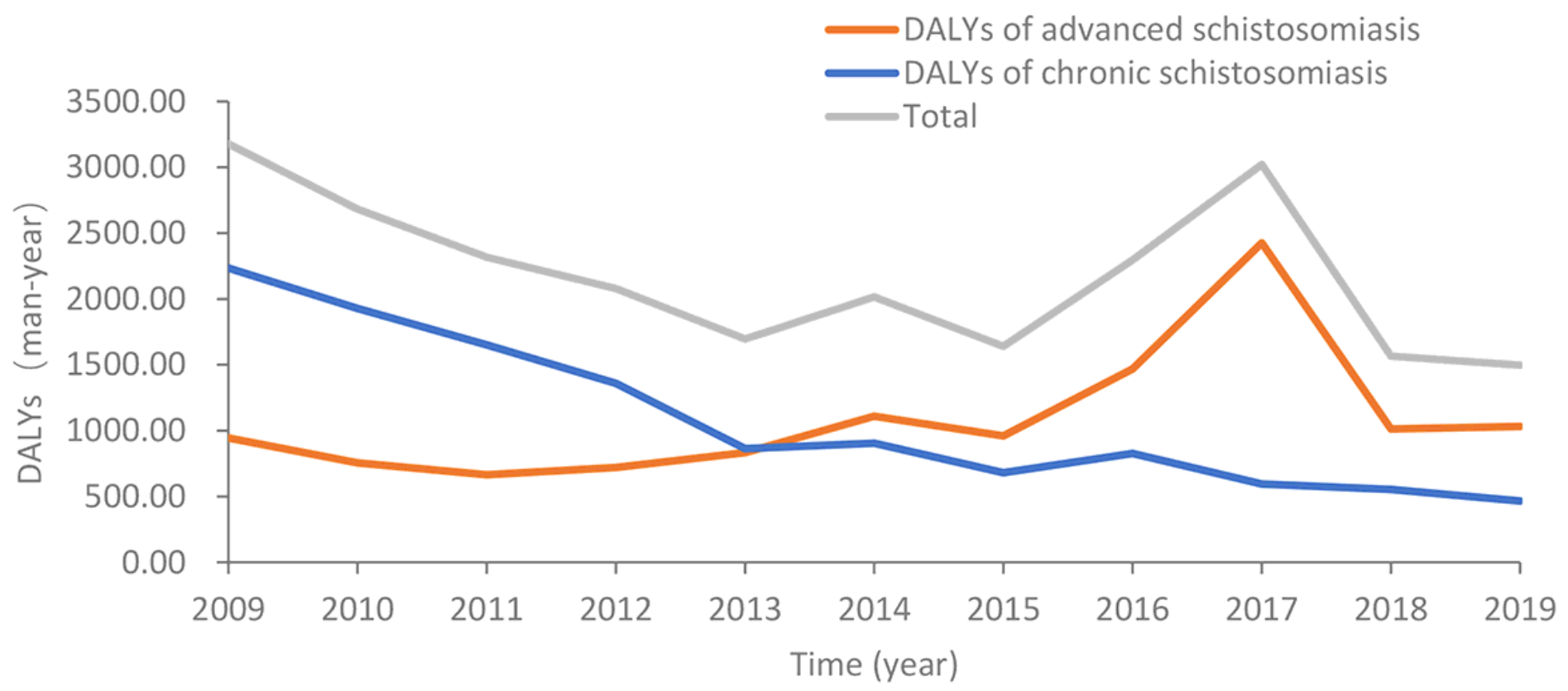

Page $8 / 9$ 
Figure 1

Changes of Disability adjusted life years caused by schistosomiasis in Jiangling Country from 2009 to 2019 Notes: DALYs means disability adjusted life years.

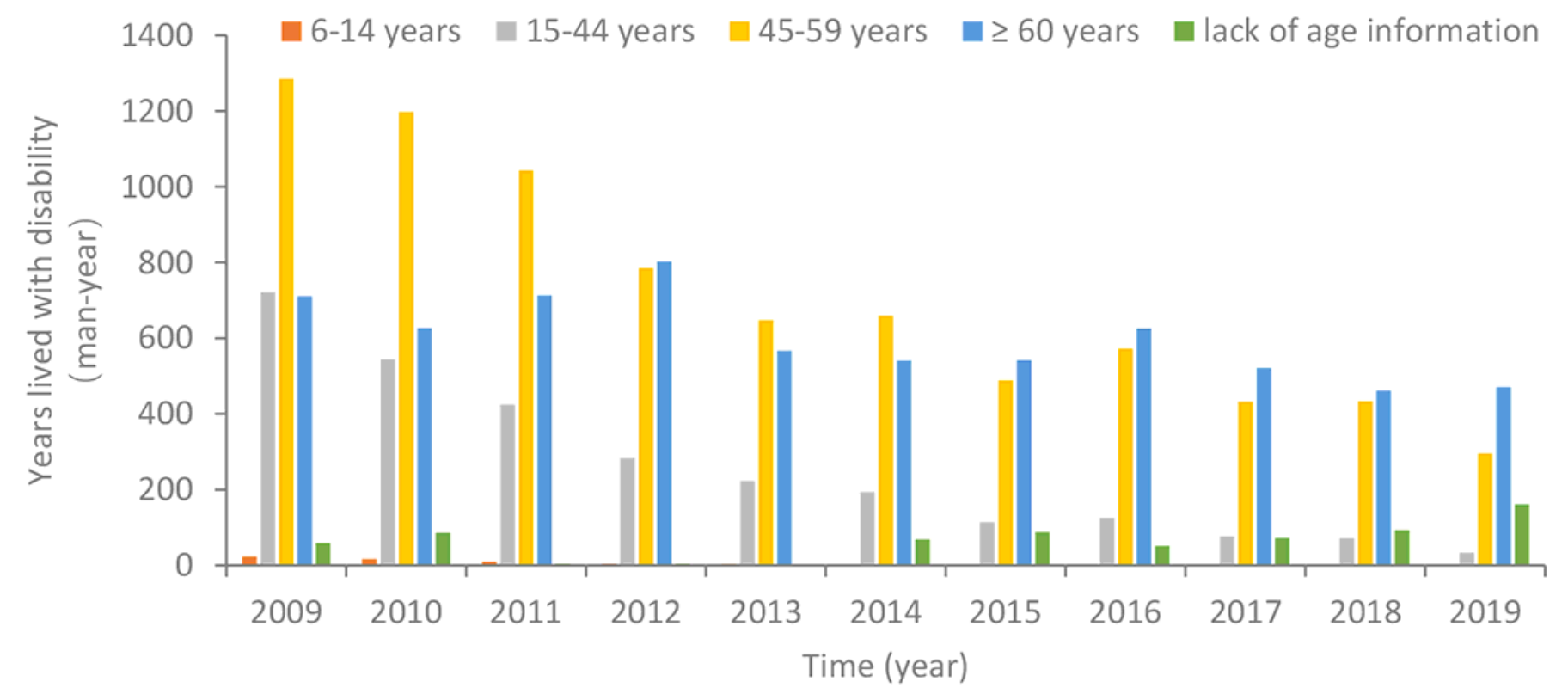

Figure 2

Changes of Years lived with disability caused by schistosomiasis by age strata in Jiangling Country from 2009 to 2019 